\title{
DOSST $\hat{\mathrm{F}}$
}

\section{Sobre las fronteras jurídicas y} sociales del trabajo asalariado en Argentina - análisis de una selección de fallos de la jurisprudencia laboral entre 1993-1997

\author{
HÉCIOR PALOMINO* Y VIRIDIANA DÍAZ ALOY** \\ Investigadores del Centro de Estudios \\ Económicos de la Empresa y el Desarrollo \\ Facultad de Ciencias Económicas. Universidad de \\ Buenos Aires. Argentina
}

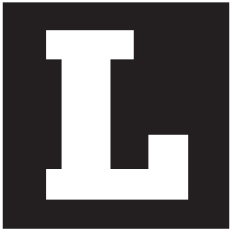

as tendencias actuales del empleo integran un proceso más vasto de transformación de la sociedad argentina. El elevado nivel de las tasas de desocupación abierta, la creciente precarización salarial y la persistencia del cuentapropismo y de la informalidad, reflejan hoy las dificultades crecientes de inserción laboral para una mayoría de la población económicamente activa. Estas tendencias erosionaron el status del trabajo asalariado, estable y sujeto a garantías, que se había consolidado en el plano social desde mediados de siglo, pero que en la actualidad sólo da cuenta de la situación laboral de una minoría de trabajadores.

La percepción de una gran transformación en el trabajo es nítida también en el campo jurídico. En primer lugar, se asiste a una profusión legislativa, destinada según sus mentores a adaptar o actualizar los derechos laborales a las transformaciones del mundo del trabajo. En segundo lugar, se 
registran fuertes debates sobre el derecho colectivo, la naturaleza de los actores y las instancias de la negociación de las relaciones laborales. Por último, también en la jurisprudencia, ese ámbito que regula las relaciones laborales en el plano "individual", se registran cambios de importancia, y es aquí donde hemos enfocado nuestra atención.

A través de la aplicación de las normas legales, las interpretaciones de los jueces operan efectos sobre la realidad que involucra a las partes de un conflicto. De allí el interés, a la vez práctico e intelectual, que suscita la jurisprudencia referida a los cambios recientes del empleo y las formas de contratación del trabajo, enfocados en este estudio a través del análisis de los fallos referidos a la subcontratación y la dependencia laboral entre 1993 y $1997^{1}$. El análisis revela la fuerte polarización interpretativa de los jueces, que enfocan situaciones similares desde posiciones doctrinarias opuestas.

La lógica que preside las interpretaciones opuestas de los jueces sobre casos similares, se revela en principio como un énfasis diferencial en las dos dimensiones jurídicas que definen la relación de trabajo: la denominada dependencia económica, que se establece en la relación salarial, y la denominada dependencia jurídica, que se establece mediante la subordinación a las órdenes de un principal o empleador. Estas dos dimensiones son afines a la distinción clásica entre subsunción formal - que define la relación salarial -, y subsunción real del trabajo al capital, que define la subordinación en la organización del trabajo.

Uno de los hallazgos del enfoque adoptado reside en la potencia de estas dimensiones para delinear las vías de transformación contemporáneas de la relación de trabajo, dando cuenta del declive del trabajo asalariado estable y garantido, y de su sustitución por formas diferentes de inserción laboral. Estas formas pueden ser descriptas en principio como combinaciones

\footnotetext{
1 Existe actualmente cierta discrepancia sobre la capacidad de la jurisprudencia para inducir comportamientos. Según algunos especialistas, la autocomposición de los conflictos laborales cuestiona su rol, porque atenúa la recurrencia a la justicia para dirimir intereses laborales. Otros argumentos enfatizan el rol de la jurisprudencia como "orientador" del comportamiento de los actores involucrados en las relaciones de trabajo, ya que los fallos producidos por las más altas instancias, como la Corte Suprema, estimulan o disuaden la recurrencia a juicio.
} 
específicas entre contratos, que se despliegan entre la dependencia e independencia contractuales, y de relaciones organizativas, que se despliegan entre la subordinación y la autonomía respecto de la organización del trabajo. Este enfoque permite clasificar las decisiones adoptadas en el ámbito de la jurisprudencia, pero al mismo tiempo lo trasciende al vincularse con la teoría social.

La distinción entre los dos conceptos básicos de la relación de trabajo -contrato y organización-, su transformación en variables y la combinación de sus dimensiones respectivas, permiten vincular las reflexiones contemporáneas sobre las transformaciones del mundo del trabajo con los enfoques clásicos de la sociología. Es decir, con los enfoques de Marx sobre la relación de trabajo, de Durkheim sobre el contrato y de Weber sobre la organización. Este puente entre reflexiones contemporáneas y pensamiento clásico, aquí sólo esbozado, ofrece posibilidades de búsqueda tanto en el terreno de la síntesis teórica, como en el campo práctico de indagación de las tendencias de cambio social.

Cabe agregar por último que este estudio resulta de una cooperación entre investigadores de diferentes disciplinas, de sociología y derecho. En una época de transición como la actual, esta cooperación se justifica no sólo por sus hallazgos, sino también por el reconocimiento de que las antiguas certezas no resultan suficientes para comprender los nuevos fenómenos, lo que impulsa la búsqueda de claves de comprensión más allá de la propia especialidad académica.

\section{El declive del trabajo asalariado}

El deterioro de la situación económica, social y política de los asalariados constituye una tendencia notoria de los '90. En la base de ese declive pueden constatarse el aumento inédito de las tasas de desocupación abierta, la precarización salarial, la caída de la sindicalización. El objeto de 
esta presentación es explorar la relación entre ese declive y los cambios en el status jurídico de los trabajadores asalariados. Una primera aproximación al respecto la proporciona el contraste entre el diseño provisto por las normas de la Ley del Contrato de Trabajo (LCT) y la constatación de su cobertura efectiva en el mundo del trabajo.

El modelo de inserción laboral que promueve la LCT puede ser descripto básicamente como un empleo asalariado estable (o de duración indefinida), articulado con servicios de salud, institutos previsionales, derecho a la indemnización por despido y otros. Una estimación reciente ${ }^{2}$ fija en sólo 1 de cada 6 activos la proporción de trabajadores incluidos efectivamente en este modelo prototípico de asalariado. Aún cuando se trate de una estimación de la cual pueden discutirse algunos supuestos, parece una aproximación bastante realista ${ }^{3}$; ella muestra que el ámbito actual de aplicación de la LCT, que en la época de su promulgación - un cuarto de siglo atrás - sus gestores concibieron como pieza central del derecho del trabajo en Argentina, se encuentra fuertemente recortado, aunque no toda la restricción de su cobertura puede ser atribuida a los cambios de los '90.

En primer lugar, ya desde su origen la LCT excluía ciertas categorías como los empleados de la Administración Pública, los trabajadores agrarios y los trabajadores del servicio doméstico, sujetos a regímenes particulares, y también parcialmente a trabajadores como los de la construcción, sujetos también a un régimen diferenciado de estabilidad e indemnización. Como referencia, cabe señalar que los asalariados clasificados en estas categorías ascendían en 1991, según el censo de población de ese año, a unos 4

2 Godio, Julio (Coordinador), Cortina, R.; Rizzi, S. y Robles, A.J. La incertidumbre del trabajo. Ed. Corregidor. Buenos Aires, 1998. (Ver cuadros de págs. 74-75).

3 Los autores incorporan esos criterios en su texto, lo cual facilita su revisión. La estimación de $50 \%$ de asalariados en negro parece excesiva, mientras que en sentido inverso cabría restar a la cifra consignada a los trabajadores de las PYMES (empresas de menos de 50 trabajadores), sujetos a un régimen particular. Como la fuente principal utilizada es la EPH, aplicada sobre los principales mercados de trabajo urbanos, deja de lado los mercados de trabajo de las pequeñas ciudades y el grueso del trabajo rural. También subestima el empleo público, al cifrarlo en 900.000 empleados, cantidad inferior a la mitad de la registrada por el Censo de Población de 1991-del texto parece desprenderse que se excluye a los docentes y otros empleados de servicios estatales. Sin embargo, es probable que las correcciones pueden llegar a compensarse entre si, por lo que no se afectaría mayormente la cifra estimada. Como referencia, el Censo de Población de 1991 estimaba el total de la PEA en 13,2 millones. 
millones de trabajadores, es decir la mitad del total de asalariados. En segundo lugar, también quedaban excluidos de la cobertura de la LCT la mayoría de los no asalariados, algo más de 4 millones de activos ocupados según el censo de 1991. En esa condición se incluyen la categoría de "cuenta propia" y parte de los "empleadores", junto a una amplia gama de actividades que van desde la prestación de servicios profesionales hasta comerciales, artesanales, etc.; todas estas categorías se hallaban, total o parcialmente, fuera del ámbito de aplicación de la ley antes de los '90. En suma, los asalariados cubiertos por el modelo prototípico que informaba la LCT representaban en 1991 alrededor de 4 millones de personas, cifra equivalente de modo aproximado a sólo un tercio de los ocupados. Es decir que ya a principios de la década podía observarse una asimetría entre la imagen prevaleciente sobre la condición salarial "típica" y la incidencia efectiva de ésta en la estructura ocupacional.

El contraste entre el modelo normativo de asalariado y los "trabajadores realmente existentes" era ya muy acusada en 1991 de acuerdo con las cifras expuestas, aunque es probable que ese contraste no se hubiera difundido aún en la conciencia social. El tratamiento del tema escapa a los límites de este trabajo, pero puede formularse la hipótesis que el factor clave en la persistencia de ese modelo normativo en la conciencia social haya sido el peso relativo del empleo público. Éste constituía, en 1991, aproximadamente el $17 \%$ del empleo total, comprendidas todas las instancias de la Administración, los servicios de educación, salud, etc. Asimismo, durante los ' 80 se constató un crecimiento significativo de la organización y la acción sindical en este segmento ocupacional, lo cual tendió a favorecer la asimilación parcial de la estructura y comportamiento de los empleados públicos con el resto de los trabajadores. Si bien la sujeción normativa de los empleados del sector público los constituye en un status jurídico particular y los distancia del modelo "típico" de asalariado, muchas de sus características -como la estabilidad en el cargo, la cobertura de salud, la protección previsional y otras-, los acercan a ese modelo. 
Actualmente la proporción de asalariados asimilados al modelo normativo típico se ha reducido aún más. En 1998, de acuerdo con la fuente mencionada más arriba, el número de asalariados que responden al modelo de la LCT no sobrepasaba 2,4 millones. Es decir que la cantidad de asalariados cubiertos en forma "plena" por la LCT disminuyó alrededor de 40\%, con respecto a la registrada a principios en 1991. Esta evolución reciente puede vincularse con el surgimiento de otras tendencias que acotaron la cobertura de la LCT en el curso de esta década: I) la expansión de "contratos promovidos" o "relaciones especiales" que eximen a los empleadores de aportes y contribuciones previsionales y de obra social; II) la ley que regula la inserción laboral en las PYMES - las empresas de 50 ó menos empleados y un determinado nivel de facturación -; III) el crecimiento del número de trabajadores situados en áreas fronterizas del trabajo asalariado, colocados en situaciones y relaciones de trabajo ambiguas cuyas definiciones tienden a superponerse, tales como el trabajo "no registrado", el trabajo "clandestino" y otros.

Podría decirse que, en relación con el modelo promovido por la LCT, se aprecia una "erosión" de la condición contractual de los asalariados, proceso que en lo que va de la década asume múltiples formas comúnmente relacionadas con la precarización - en alusión a los contratos en los que el salario pierde su articulación automática con el sistema previsional y de salud -, o bien con las normas que garantizan estabilidad, indemnización por despido y otros institutos. En esta vía de precarización se situaba antes comúnmente al trabajo "clandestino" y/o "no registrado", así como el trabajo realizado bajo regímenes especiales como los mencionados (en la construcción, el servicio doméstico, el trabajo agrario) y modalidades de corta duración como el trabajo eventual, con la posible intervención de agencias de ese tipo de servicios. Ahora se suman en este plano los trabajadores legalmente precarizados, sea bajo la forma de contratos "promovidos" o modalidades especiales - pasantías, aprendizaje -, o bien bajo regímenes particulares como el correspondiente a las PYMES.

Estas diversas formas de erosión del trabajo asalariado operan dentro 
de los límites de sus "fronteras internas". Se trata de formas contractuales que acusan una "pérdida" de garantías, institutos de protección y servicios articulados anteriormente con el modelo normativo de trabajo asalariado sancionado por la LCT. Cuando esa "pérdida" es conformada legalmente, se acompaña de la emergencia simultánea de lo que Alain Supiot denomina un derecho laboral de "segundo tipo", para aludir a la devaluación del derecho del trabajo tradicional que suponen esas nuevas formas contractuales. Cuando dicha pérdida no es conformada legalmente se ingresa en el terreno del trabajo "no registrado" y en sus formas más perversas en el trabajo "negro" o "clandestino". Parece más o menos obvio que la situación de desempleo, extendida a vastas capas de la población en la actualidad, induce a aceptar estas formas de inserción asalariada devaluadas respecto del derecho del trabajo tradicional. Tanto más en un país como Argentina, donde el trabajo constituye un verdadero paradigma de los derechos sociales y donde ya desde mediados de siglo los institutos y servicios sociales estuvieron articulados con el salario. Pero lo que importa señalar es que más allá de su perversidad, estas formas suponen una condición salarial de base. De allí el uso de la metáfora referida a las "fronteras internas" del trabajo asalariado.

Asimismo se expandieron durante los '90 otras modalidades de inserción laboral que difieren de las relaciones de trabajo incluidas en la LCT. Se trata de modalidades que operan en las "fronteras externas" del trabajo asalariado, ya que constituyen "prestaciones" reguladas por mecanismos jurídicos derivados de la esfera del derecho civil o mercantil, e involucran una transformación notable en el status del trabajo: mientras que en el derecho del trabajo se reconoce una desigualdad de origen de los trabajadores - para quienes la norma jurídica promueve garantías diversas en busca de su nivelación con la contraparte empleadora -, la esfera civil o mercantil en cambio, concibe a las partes del contrato en un plano de igualdad. Este sendero de erosión del status jurídico de los asalariados a través de sus fronteras externas es el que presenta mayores dificultades de 
interpretación, y no sólo para los jueces, ya que ponen en juego las representaciones sociales del trabajo y, por lo tanto, lo que algunos autores denominan la construccción social de los mercados de trabajo ${ }^{4}$.

En la época que el trabajo asalariado estable y garantido constituía la modalidad predominante, sus fronteras se localizaban en sus "formas fraudulentas", a través de las cuales se buscaba disfrazar la relación de dependencia laboral. Dentro de los límites físicos de un establecimiento que proveía un ámbito bastante preciso y "visible", podía situarse cómodamente una determinada organización del trabajo que distribuía roles directivos y subordinados claramente delimitados. Las formas fraudulentas surgían de la falta de registro de trabajadores subordinados, o bien del intento de disimular la dependencia laboral bajo otras formas de contratación.

Actualmente ese ámbito aparece desdibujado por procesos de reestructuración empresaria que estimulan la derivación a terceros (externalización) de partes de los procesos productivos de bienes o servicios ${ }^{5}$. Dentro de un mismo espacio físico, coexisten actividades laborales desarrolladas por diversas empresas, entretejidas en redes de contratación y subcontratación en el seno de las cuales no resulta fácil trazar los vectores de dependencia laboral. Al mismo tiempo, los límites de las empresas coinciden cada vez menos con los ámbitos físicos del establecimiento, extendiéndose por vías diversas hacia el espacio económico de los mercados, mediante redes de comercialización y distribución singulares, y hacia el espacio doméstico mediante las posibilidades actuales de operar el "trabajo a distancia" u otras modalidades.

El trabajo realizado en este nuevo contexto se sujeta a nuevas moda-

\footnotetext{
4 Bryn Jones. The Social Constitution of Labour Market. En Changing Forms of Employement. Editado por Rosemary Crompton, Duncan Gallie y Kate Purcell. Ed. Routledge, Londres, 1996.

5 Novick, M. y Gallart, M. A. Coord. (1998): Competitividad, redes productivas y competencias laborales. Ed. CINTERFOR-OIT y Red de Educación y Trabajo. Buenos Aires. Abreu de Paiva, A.; Sorj, Bila y Ramalho, J. R. (1995): Tercerizacao y precarizacao. Os impactos sociais da reestructuracao industrial no Rio de Janeiro. Paper presentado al XIX International Congress of LASA, September. Washington. Walter, J. y Senén González, C. (1996): Modernización tecnológica sistémica, políticas de recursos humanos y relaciones laborales en la telefonía argentina tras la privatización. Documento presentado en el II Congreso Latinoamericano de Sociología do Trabalho. Sao Paulo, 1 al 5 de diciembre de 1996.
} 
lidades de contratación y de organización. En muchos casos los contenidos y la naturaleza del trabajo permanecen idénticos, ya que las tareas correspondientes a diversos oficios no ha variado mayormente. Es el caso por ejemplo de los conductores de vehículos, de los electricistas en la construcción, de los operarios en establecimientos industriales, de los trabajadores de servicios involucrados en tareas de limpieza, seguridad o catering. Pero varían considerablemente la organización social del trabajo y sus representaciones simbólicas. En el plano de la organización se registran cambios radicales en el sentimiento de "pertenencia", ya que compartir un mismo espacio físico o entregar el resultado del trabajo a una misma empresa ya no bastan para delinear un suelo común de pertenencia entre trabajadores. En el plano simbólico se escinde la figura tradicional del "trabajador dependiente", sujeto por un contrato de trabajo a la organización dispuesta por el empleador, de la figura del "trabajador independiente" cuya sujeción a la empresa para la cual realiza sus tareas deriva de un contrato de índole mercantil.

El impacto social de estos procesos de reorganización y cambio contractual del trabajo son demasiado vastos como para tratarlos aquí en detalle, aunque existe cierto consenso sobre sus repercusiones en algunos ámbitos. Baste señalar al respecto sus consecuencias negativas sobre los sindicatos, ya que afectan el núcleo central de identidad laboral que preside su capacidad de reclutamiento y afiliación, y que ha sido señalado por numerosos analistas del tema. En cambio, con respecto al origen o las causas de estos procesos existen interpretaciones disímiles, que opone a quienes acentúan la cuestión del impacto del cambio tecnológico en la reorganización del trabajo, frente a quienes enfatizan el carácter social de los procesos de reestructuración organizativa y flexibilización laboral impulsados por los empresarios. Como ambos factores operan frecuentemente de modo simultáneo y se influyen mutuamente, es habitual también su consideración conjunta, sobre todo en los análisis de casos específicos. 


\section{Las fronteras del trabajo asalariado}

El ámbito del debate contemporáneo sobre las relaciones de trabajo es sin duda universal, tal como lo testimonian las posiciones surgidas en torno a la articulación entre las normas de la Organización Mundial de Comercio (OMC) con las de la Organización Internacional del Trabajo (OIT), donde se trata de delimitar la frontera entre los contratos laborales y los mercantiles. Asimismo, las discusiones generadas en la OIT acerca de la posibilidad de incorporar un régimen de trabajo en subcontratación, como una nueva modalidad laboral ${ }^{6}$, permiten esclarecer los aspectos involucrados en la relación de trabajo.

La definición del régimen de trabajo en subcontratación, tal como fue propuesta al debate en la OIT, combina las nociones de dependencia y subordinación laboral, que permanecen superpuestas en el status jurídico del asalariado. En la dimensión contractual el asalariado es "dependiente", en el sentido que vende su fuerza de trabajo colocándola a disposición del empleador. Se diferencia de este modo del trabajador "independiente", que no vende su fuerza de trabajo sino el producto o resultado de su aplicación, asignando un precio al producto/servicio realizado. Podrían reservarse las nociones de dependencia/ independencia para aludir a esta dimensión contractual.

La segunda dimensión se vincula con la organización del trabajo. En la forma asalariada, el trabajador se "subordina" a su empleador: acepta que su labor será orientada, dirigida y supervisada por éste o por quien funcione en la organización como su representante - sea jefe, gerente o supervisor. En el trabajo "autónomo" en cambio, el propio trabajador organiza sus tareas: al usuario del producto o servicio le resulta en principio indiferente el modo en que éste fue realizado y lo valora sólo por sus resultados. Podrían reservarse las nociones de subordinación/autonomía para aludir a este aspecto de la organización

6 Informe V (2B) Addendum. Comisión del Trabajo en Subcontratación. OIT. 86ª reunión. Ginebra, junio de 1998. 
del trabajo ${ }^{7}$.

La subcontratación, de acuerdo con la definición propuesta en la OIT, combina de modo singular estas dos dimensiones. El trabajador en régimen de subcontratación está subordinado a la empresa que lo contrata, pero no es empleado de la misma. Para comprender este galimatías conviene recurrir a la distinción mencionada: quien trabaja en régimen de subcontratación está sujeto a la "subordinación" desde el punto de vista de la organización, pero no se sitúa en una relación de dependencia desde el punto de vista contractual y es considerado, inversamente, como un trabajador "independiente".

\section{Organización}

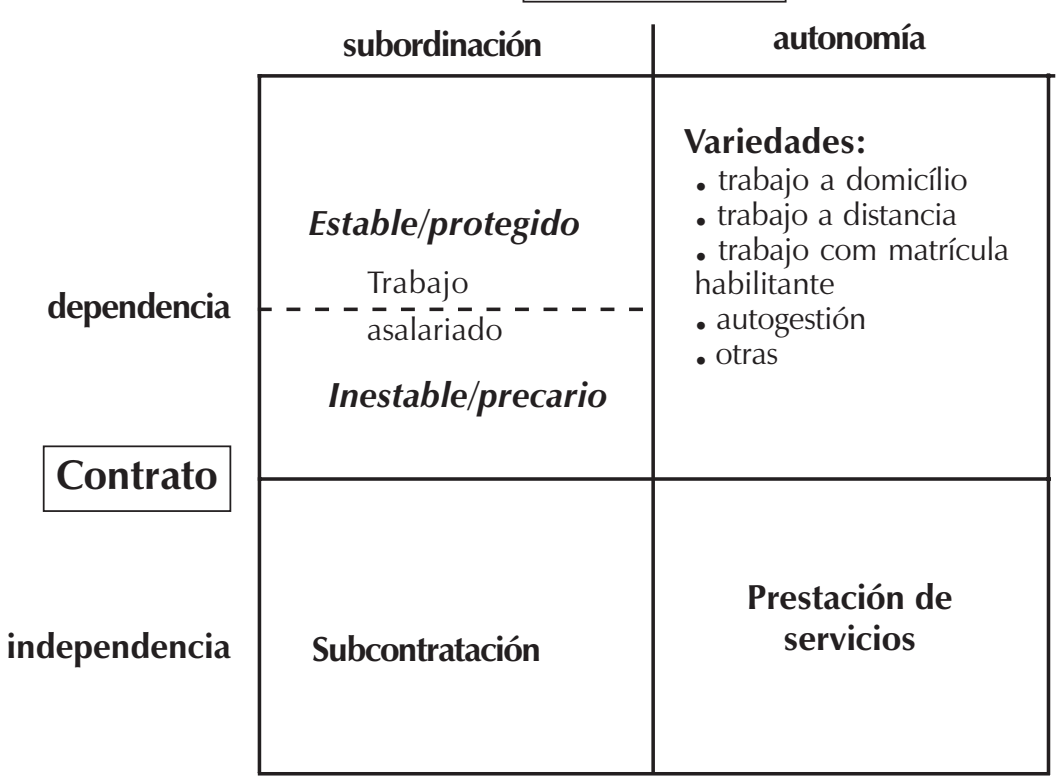

7 Pawlowski de Pose, A..L. La ajenidad de/ riesgo como factor tipificante. En Revista Derecho del Trabajo № $5_{+}$ mayo de 1998. Ed. La Ley. Buenos Aires. Págs. 1000-1001. La autora refiere diferentes doctrinas acerca de las nociones de dependencia económica y de subordinación jurídica, concluyendo en la posibilidad de resolverlas (sobre todo entre trabajo "autónomo" y "dependiente") aplicando las nociones de "riesgo económico" y de "ajenidad", usuales en España, enfoque que ilustra el impacto de las nuevas formas de empleo en el debate social. 


\section{Clasificación de las modalidades de trabajo según las relacio- nes contractuales y la organización del trabajo}

El casillero que combina la dependencia contractual con la subordinación en la organización corresponde a la forma típica y fácilmente reconocible del trabajo asalariado. En este casillero podemos ubicar el sendero de precarización mencionado: el trabajo asalariado se desdobla entre "protegido y estable" y "no protegido e inestable". Este corte indica lo que denominamos la "frontera interna" del trabajo asalariado.

El casillero que combina la independencia contractual con la subordinación en la organización corresponde a la propuesta de definición de la OIT sobre el "trabajador en régimen de subcontratación". Aquí se pueden localizar diversas modalidades, como las que predominan en la industria de la construcción, donde la subordinación en la organización del trabajo se garantiza a través de cláusulas contractuales ad-hoc. La noción de independencia tiene aquí dos sentidos diferentes: uno se refiere a la prestación de trabajos en una empresa por parte de los asalariados de otra empresa; esto involucra relaciones de trabajo trilaterales, que se multiplican según la profundidad de la cadena de subcontratación. El otro sentido corresponde a la contratación directa por parte de la empresa usuaria del trabajo; en estos casos la independencia del subcontratado no lo exime de la subordinación organizativa, aunque disfruta (teóricamente) de la posibilidad de "moverse" de un contrato al siguiente.

El casillero que combina la dependencia contractual con un rol autónomo en la organización del trabajo comprende una gran variedad de modalidades que cuesta resumir en una fórmula sintética, ya que integra desde antiguas formas de trabajo a domicilio hasta el actual "trabajo a distancia". Incluso podría extenderse la noción e integrar en ella la jerarquía funcional (ya que por ejemplo también los gerentes son asalariados) y/o estilos contemporáneos de gestión de recursos humanos. En la modalidad que corresponde al "trabajo a distancia", si bien el trabajador mantiene una 
relación salarial, realiza su actividad fuera del ámbito de control y supervisión directa del empleador: es el caso típico de los conductores de vehículos. Otra corresponde a ciertas formas modernas de gestión, con predominio de relaciones "horizontales", en las que los trabajadores pueden organizarse por sí mismos de modo autónomo. Esta forma llega a constituir en ocasiones un embrión "autogestionario" que, si bien poco frecuente, puede observarse en tareas de mantenimiento de los servicios de distribución a través de líneas (de gas, por ejemplo). Una tercera variedad alude al trabajo de profesionales u otras categorías dotadas de cierta autonomía en la prestación de trabajo que proviene de una matrícula o certificación habilitante.

Por último, en diagonal respecto del trabajo asalariado se sitúa la prestación de servicios, independiente desde el punto de vista contractual y autónomo desde el punto de vista organizativo. En esta figura se establecen contratos de tipo mercantil, no laborales, cuyas formas pueden ser sumamente variadas. Algunas pueden incorporar especificaciones tan detalladas por parte del contratante, que la autonomía puede no resultar más que ilusoria, como en los contratos de grandes empresas cuyos controles y mecanismos de supervisión tornan en cierta medida ilusoria la independencia contractual. Por ejemplo, la certificación de normas de calidad en los procesos involucra la auditoría más o menos permanente de los proveedores por parte del contratante. Es posible que cuando la contratación se establece entre partners, las normas de la prestación pueden ser negociadas, en tal caso la idea de "autonomía" cobra sentido pleno. En cambio cuando una de las partes es una gran empresa lo más probable es que la autonomía sea sólo relativa, manifestándose de hecho una relación de subordinación. Tal vez de las peores, ya que aparece revestida bajo la forma de un contrato entre iguales libremente aceptado por el contratado.

De todas las figuras contempladas en el esquema, la que ofrece mayores dificultades de interpretación es la subcontratación ya que se establecen allí vínculos trilaterales que, de un modo u otro, integran a los restantes: 


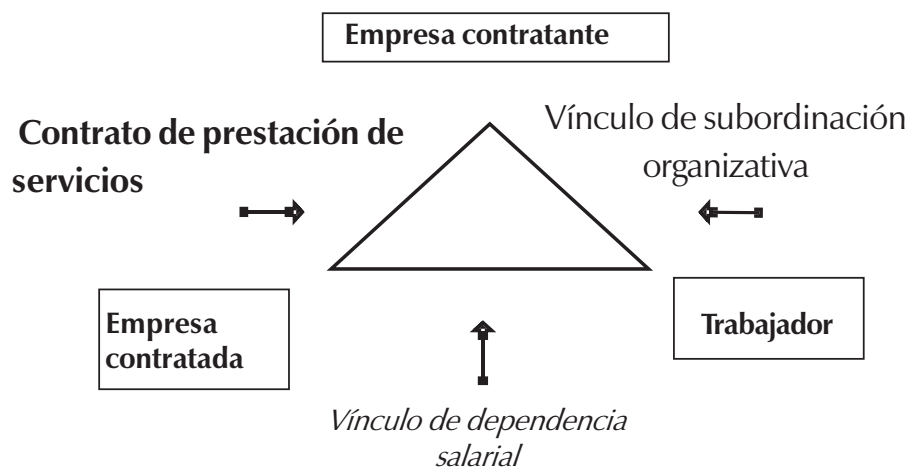

De acuerdo con la terminología expuesta, el trabajador individual a) se halla subordinado a la organización del trabajo de la empresa contratante, b) tiene un contrato como asalariado dependiente de la empresa contratada, c) su trabajo está mediado por un contrato de índole mercantil entre la empresa contratante y la contratada.

Tal como se verá en detalle en los próximos capítulos, los vínculos trilaterales en las relaciones de subcontratación generan disputas judiciales donde las resoluciones de los jueces pueden orientarse según el vínculo que se enfatice. La solidaridad entre empresas supone privilegiar la subordinación organizativa, y se concibe al trabajador "como si" fuera salarialmente dependiente de la empresa contratante. La denegación de la solidaridad supone privilegiar los vínculos mercantiles entre empresas, concibiendo al trabajador exclusivamente en la perspectiva de su dependencia salarial con la empresa contratada.

Los esquemas de interpretación jurídica de la dependencia laboral

La noción jurídica de "dependencia" se sitúa en el centro del debate actual, un escenario de complejas relaciones entre el encuadre jurídico, las nuevas formas 
de organización del trabajo y las nuevas tendencias sociales en el mercado de trabajo. Aún cuando en este escenario no es fácil delimitar los contornos de la noción jurídica de "dependencia", puede reflexionarse sobre su capacidad para captar situaciones atípicas o especiales ${ }^{8}$.

La vigencia del modelo de trabajo que la LCT promovía se redujo, de acuerdo con lo expuesto en el capítulo anterior. Tampoco son menores los cambios relativos al status jurídico de los asalariados: la promulgación de nuevas normas jurídico-laborales durante los '90, si bien sostuvo formalmente los viejos institutos, socavó sus bases constitutivas mediante, por ejemplo, numerosas excepciones a los criterios generales de continuidad e indeterminación del vínculo laboral. Por otra parte, las nuevas modalidades contractuales tienden a desarticular el salario de la cobertura médica y previsional y de otros institutos de protección tales como la indemnización por despido, que antiguamente eran contenidos automáticamente en la relación de trabajo. Es decir, las fronteras internas de la condición de asalariado se están transformando mediante normas legales que inducen su precarización.

Pero se constatan también otras tensiones sobre el trabajo asalariado que actúan sobre sus fronteras externas, a través de encuadres jurídicos en contratos de índole diversa a los laborales, sea civil, mercantil u otra. Estas fronteras externas se corresponden, en el plano del análisis jurídico, con la noción de dependencia en sus formas económica y jurídica ${ }^{9}$. La dependencia económica - en cuanto ajenidad en los medios de trabajo, frutos y riesgos

8 Pueden verse las ponencias que sobre el tema "Actualidad y contenido del concepto de dependencia laboral" fueron presentadas a las XII Jornadas Nacionales de Derecho del Trabajo y de la Seguridad Social, realizadas en septiembre de 1995 por la Asociación Argentina de Derecho del Trabajo y de la Seguridad Social.

9 La dependencia económica supone que "el trabajador se asegura el cobro de una retribución, otorgando por anticipado al empleador el derecho de disponer del producto que pueda resultar de su actividad física o mental utilizada de acuerdo con los términos del contrato y de la ley, para que este obtenga la mayor utilidad posible o soporte los riesgos de no poder negociar el producto, de hacerlo a menos del costo o de la insolvencia del comprador. La dependencia jurídica es aquella por la cual "un trabajador en forma voluntaria se incorpora a una empresa total o parcialmente ajena y coaccionado por la posibilidad de que el empleador haga cesar la vinculación en caso de desobediencia, se compromete a acatar órdenes y directivas que le impartan las personas que tienen a su cargo el ejercicio efectivo del poder de dirección, en tanto no se aparten de los términos del contrato y demás normas del derecho objetivo que resulten aplicables". Perugini, E. "La dependencia laboral”, DT XLII-A, pág.88. 
por parte del trabajador - podría localizarse dentro de la dimensión contractual de la relación de trabajo. El recurso cada vez más frecuente a diversas formas de subcontratación plantea la cuestión del debilitamiento de los vínculos de responsabilidad empresaria en garantizar las condiciones de empleo de los trabajadores. La dependencia jurídica se corresponde centralmente con la organización del trabajo. El trabajo asalariado en su forma típica supone la heteronomía del trabajador, es decir su sometimiento a la dirección y mando del empleador. Como contrapartida, la autonomía en la organización del trabajo desplaza la frontera del contrato hacia la esfera mercantil de la prestación de servicios.

En síntesis, el debate en el plano jurídico articula cuestiones diversas como I) "dependencia"/condición de laboralidad, II) homogeneidad/ diferenciación en la legislación tutelar y III) cambios en las formas de vinculación contractual. En este debate, la noción de dependencia laboral ${ }^{10}$ se expresa en diversos esquemas conceptuales.

Uno de los esquemas conceptuales identifica la dependencia como una figura social "promedio" construida a partir de la abstracción de ciertos rasgos de la relación salarial. Toda situación cuyo status jurídico sea cuestionado se resolverá por operaciones de aproximación a ese tipo promedio, que expresa la modalidad de inserción más frecuente en el mercado de trabajo. Los efectos de tal operación son dicotómicos: si se da por configurada, la dependencia introduce la situación en la esfera del contrato de trabajo y de la legislación laboral, en caso contrario la excluye de su ámbito. Esta tesis se ve particularmente afectada por las transformaciones contemporáneas de la organización del trabajo: la dependencia pierde su carácter de figura prototípica y se convierte en una más de las múltiples alternativas de inserción laboral. Es decir que la avalancha de situaciones atípicas o especiales, irreductibles a un nuevo prototipo dominante, torna difícil la identificación de un promedio.

En otro esquema se formula una conceptualización flexible de la

10 Ver Goldín, Adrián: "El concepto de dependencia laboral y las transformaciones productivas". Ponencia presentada en las jornadas citadas. 
noción de dependencia, que la jurisprudencia puede adaptar a distintos contextos de organización del trabajo. Se ha sostenido ${ }^{11}$ que la dependencia laboral admite, por razones coyunturales, ciertas figuras que atenúan las garantías legales para adaptarla a las tendencias vigentes en el mercado de trabajo. En este enfoque la dependencia puede contener figuras, como la del contrato de aprendizaje, que sustentan lógicas que combinan certidumbres y riesgos. En líneas generales se admite que la paulatina desaparición de la lógica protectoria antes dominante, que estaba constituida por pisos, umbrales o topes, se podría ir reabsorbiendo a través de estas nuevas figuras.

Cabe además una tercera alternativa, que reemplazaría la noción de dependencia por otras más comprensivas como el trabajo "a secas"12. Tal apropiación de una nueva categoría base posibilitaría tal vez la construcción de un ordenamiento más plural, basado en lógicas protectoras más abarcativas, pero menos intensas. Esta alternativa tiene la virtud, más allá de su factibilidad, de ordenar algunas de las cuestiones subyacentes en el debate y que no siempre se formulan expresamente.

Profundizando este último enfoque, se trataría de distinguir dentro de la condición salarial los aspectos atinentes al trabajo stricto senso de su articulación social. En este sentido las garantías en torno a las condiciones de trabajo, de su desempeño efectivo, pueden ser diferenciadas de su reproducción social, es decir del acceso a servicios de salud, de educación, de vivienda, del sistema previsional, etc. Es posible que este enfoque no haga más que reenviar los problemas hacia otro lado, en el sentido que lo que antes se resolvía a través del trabajo asalariado deba resolverse ahora en el terreno de la seguridad social, o de los derechos sociales en general, sin articularlos necesariamente con el trabajo. A esto debería agregarse el debate que plantearía en en el terreno del derecho colectivo de trabajo, ya que muchas cuestiones vinculadas con derechos sociales son también con-

\footnotetext{
11 Vazquez Vialard, A.: "El concepto de dependencia laboral frente a nuevas prácticas contractuales. ¿Debe desaparecer o transformarse?". Ponencia presentada en las jornadas citadas.

12 Goldín Adrian O., "El concepto de dependencia laboral y las transformaciones productivas", Ponencia presentada a las Jornadas citadas.
} 
sideradas en el plano de los convenios colectivos o de su gestión a través de sindicatos. Es decir que en última instancia, la alternativa de considerar el trabajo "a secas" requiere resolver "por otra vía" lo que antes se resolvía por la LCT a la vez que por la existencia de otras instituciones.

Es posible que este debate jurídico no haga más que expresar las grandes líneas de un debate social y político más amplio, aún incipiente, que habrá de desplegarse más tarde o más temprano ya que el abroquelamiento en posiciones cerradas difícilmente pueda perpetuarse indefinidamente. Por un lado resulta difícil sostener un modelo normativo de trabajo asalariado erosionado por las condiciones realmente existentes y, por otro lado, algunas de estas condiciones son tan gravosas para los trabajadores que difícilmente se las pueda atenuar con el argumento de la adaptación a una supuesta modernización u otros eufemismos.

Para afrontar estos problemas se requiere el esclarecimiento de algunas cuestiones básicas que ni en el plano jurídico, ni en la teoría económica o social, aparecen resueltas aún. Una forma de profundizar el análisis consiste en retomar el planteo que diferencia las dimensiones de la organización y de las relaciones contractuales de trabajo formulado anteriormente $^{13}$, y que reaparece en el debate jurídico sobre la dependencia laboral. Este planteo permite analizar situaciones de: a) dependencia contractual con componentes de autonomía, habilitadas por el propio empleador como espacio de decisiones libradas al trabajador; y b) situaciones de calificación independiente - autónoma o no laboral en el lenguaje jurídico - pero con componentes de subordinación o heteronomía en la organización del trabajo. 


\section{Análisis sobre un recorte de jurisprudencia laboral}

La fuente utilizada son los extractos de fallos, organizados en "sumarios", editados por la Revista Derecho del Trabajo ${ }^{14}$ en el período 1993-1997, sobre los casos tratados en las instancias superiores de apelación, en relación con las voces referidas al Contrato de Trabajo:

I) Ambito de aplicación de la legislación laboral común;

II) Concepto y caracteres esenciales del contrato de trabajo;

III) Sujetos del contrato de trabajo

Sobre un total de 83 sumarios se realizó un análisis de carácter exploratorio, destinado básicamente a relevar los argumentos e indicios considerados por los jueces, sin pretensiones de validez estadística. Los sumarios se clasificaron en base a dos ejes: a) sumarios que proporcionan argumentos en torno a las consecuencias derivadas de la subcontratación relativos a la determinación de la solidaridad/no solidaridad entre empleadores, y b) sumarios que proporcionan argumentos en torno a la calificación contractual del vínculo, es decir los relativos a la definición de su carácter laboral/no laboral.

El material fue ordenado según los siguientes items: 1) Las fronteras del trabajo asalariado con la subcontratación, y 2) Las fronteras del trabajo asalariado con la prestación de servicios. A su vez, cada item incluye una subdivisión en ciertas áreas de actividad.

\subsection{Las fronteras del trabajo asalariado con la subcontratación}

Las fronteras del trabajo asalariado con la subcontratación se establecen en torno al vínculo de solidaridad entre la empresa contratante, usuaria del trabajo, y la empresa contratada que establece un vínculo salarial con el prestador de trabajo. El eje jurídico de este vínculo "trilateral" -empresa 
contratante, empresa contratada, trabajador- consta en el artículo 30 de la LCT. Este discernimiento judicial tiene importancia para el desarrollo de las tendencias actuales de terciarización y externalización de procesos productivos y de servicios en las grandes empresas. El aspecto central que se discute en sede judicial es el carácter "normal" y "específico" del trabajo requerido por las empresas. Si las actividades realizadas por el trabajador en la empresa contratante son "normales" y "específicas" de ésta, sus condiciones deben ser similares a la de los trabajadores directos de dicha empresa, lo cual funda la responsabilidad de la empresa usuaria respecto de los subcontratados (trabajadores aportados por terceras empresas). Esta responsabilidad es difícil de precisar, tal como se verá en el análisis de los diferentes casos.

a) Subcontratación en la cadena de comercialización

Estos casos se refieren a la subcontratación de actividades en empresas que integran algunas o todas las fases de producción, almacenamiento, distribución, transporte y comercialización. Dos de los casos considerados se refieren a demandas contra una misma empresa y dieron lugar a fallos de la Corte Suprema (Luna c/Agencia Marítima Rigel y Gauna c/Agencia Marítima Rigel S.A) que lo constituyeron como un leading case en el que se estableció, como pauta general, el rechazo de la solidaridad entre empresas respecto del personal de la subcontratada. El argumento clave fue que las actividades de la subcontratada no constituían "actividades normales y específicas" del contratante, complementado por un criterio de especialización que escinde la comercialización respecto del almacenamiento o estibaje, lo cual difiere de la tradición de los exportadores de proveerse el servicio de estiba.

En los restantes casos referidos a la comercialización, en tres se concedió la solidaridad entre empresas respecto del personal subcontratado, mientras que en otras tres fue denegada. En los casos con resolución posi- 
tiva el criterio determinante fue la identidad de objetivos entre empresas productoras y las dedicadas a la gestión de ventas, concibiendo ésta como una actividad "normal y específica" de las primeras. En los casos en que se rechazó la solidaridad, los argumentos se basaron en a) la especialización, que diferencia las actividades "normales y específicas" de una fábrica de concentrados con los de una elaboradora y distribuidora que utiliza aquellos como insumos; b) los términos del contrato comercial, que no responsabiliza "a los concedentes por las deudas laborales de los concesionarios" y c) el hecho que la reposición de productos en supermercados no configura una "unidad técnica de ejecución" con la empresa que los elabora.

b) Subcontratación en diversas actividades "reestructuradas"

En segundo lugar pueden agruparse un conjunto de actividades sujetas a procesos de reestructuración. En un caso los jueces aceptaron la solidaridad entre una empresa de relevamiento sismográfico y una empresa petrolera, ya que es una actividad que se utiliza casi exclusivamente en esta industria. Un criterio similar asignó la responsabilidad solidaria de una empresa telefónica con una subcontratada para la instalación de cables telefónicos, ya que no se concibe la prestación del servicio sin éstos, por lo que cabe considerarla una actividad normal y específica de la primera. En la subcontratación de actividades de una empresa alimenticia se afirmó la solidaridad en base a que el prestador de trabajo no poseía establecimiento, herramientas, profesionalidad, organización y autonomía financiera, mientras que la empresa usuaria era dueña del establecimiento donde se realizó el trabajo.

En sentido contrario a la solidaridad se resolvió un juicio encarado contra la antigua compañía nacional de teléfonos, vinculado con la impresión de guías telefónicas, ya que su distribución no se consideró una actividad específica y cotidiana de aquella. 
c) Servicios tradicionalmente terciarizados

En los casos referidos a actividades de servicios de limpieza, seguridad o catering que comúnmente son terciarizadas, la existencia de empresas especializadas contribuye sin duda a su externalización. Sin embargo, no son concebidas por los jueces de modo unívoco, ya que en algunos casos se rechaza la solidaridad entre empresas y en otros se acepta. Resulta llamativa la diferente apreciación de los jueces sobre este servicio: de los 5 casos analizados, en dos los jueces confirmaron la solidaridad entre empresas y en tres la denegaron.

La confirmación judicial de la solidaridad se estableció en relación con a) un laboratorio, basándose en que las actividades de limpieza son inescindibles de su actividad e indispensables para el logro del fin empresario; b) una empresa de seguros, donde si bien las tareas de limpieza no son específicas, resultan necesarias para su normal desenvolvimiento.

El rechazo de la solidaridad se basó a) en el caso de una fundación, en que las actividades de limpieza aunque sean permanentes y habituales, no son específicas; b) en el caso de un banco se definió que los trabajos de limpieza no corresponden a la actividad normal y específica del establecimiento; c) en otro caso se estableció que si bien la limpieza puede considerarse normal en cualquier establecimiento, no pueden calificarse como específicas ya que resultan escindibles del objeto de la empresa.

En relación con los servicios de comidas, de los cuatro casos analizados 3 fueron resueltos mediante la atribución de solidaridad a la institución contratante y en 1 caso se rechazó el vínculo de solidaridad. En la admisión de solidaridad los argumentos fueron: a) el servicio de comida en un sanatorio hace a su actividad normal y específica y determina la responsabilidad solidaria con la empresa encargada de la prestación; b) la actividad del concesionario de un restaurante en las instalaciones de un club es normal y específica de éste ya que, "de conformidad a las propias costumbres del país", no puede escindirse la actividad social recreativa y deportiva que cumple la institución, 
del complemento gastronómico; c) el contrato de concesión suscripto entre la Bolsa de Cereales y un tercero para que atienda el servicio de restaurante destinado a socios e invitados, la hace solidariamente responsable ya que integra una actividad "accesoria necesaria", dada la importancia de la actividad social que complementa la principal. En el único caso analizado en que se denegó la solidaridad se concluye en que la actividad gastronómica cumplida por la concesionaria en un club náutico "no integra los fines normales y específicos de éste".

Por último, los servicios de seguridad prestados a una entidad financiera fueron considerados propios de su actividad normal y específica ya que está obligada a custodiar los valores depositados por los ahorristas, por lo que es responsable en forma solidaria con las empresas de seguridad por los accidentes de trabajo que sufran sus empleados.

\subsection{Las fronteras del trabajo asalariado con la prestación de servicios}

La frontera entre la figura del trabajo asalariado y la figura de la prestación de servicios resulta clave para deslindar el campo de aplicación del derecho del trabajo respecto del derecho mercantil y civil. El criterio de dependencia/independencia contractual busca elucidar si quien trabaja recibe un salario o un pago de otro orden. Pero esta frontera está mediada por otra, vinculada con los márgenes de decisión dentro de una organización del trabajo respecto de la cual quien trabaja puede disponer de diversos grados de autonomía. Las ocupaciones sobre las que se busca definición judicial, en la muestra analizada, configura algunas situaciones típicas: profesionales -sobre todo médicos-, trabajo a domicilio; transporte y distribución de bienes y de personas. 
a) El trabajo de los profesionales

La autonomía de los profesionales en la organización del trabajo se funda en una matrícula habilitante que delimita su campo de actividad y excluye a quienes no la poseen. Esto resulta clave en el ejercicio de la medicina, aunque en términos de organización social el desempeño profesional de los médicos se vincula con tres modalidades diferentes: I) el viejo modelo de profesional liberal dotado de consultorio privado propio, II) su inserción en un hospital o sanatorio, y III) su vinculación con una red o sistema de atención y derivación de pacientes.

Las situaciones emergentes responden básicamente a las dos últimas formas de organización; se trata de demandas en las que los médicos buscan probar que sus vínculos con instituciones y redes corresponden a contratos de trabajo. Las decisiones de los jueces se fundan en criterios que privilegian por un lado el rol de los profesionales en la organización, y por otro la forma de su remuneración.

I) En los casos en que se decide la existencia de un vínculo laboral, los criterios para determinarlo se relacionan con la subordinación en la organización del trabajo: I) fijación de horarios y días predeterminados para la atención de pacientes, durante los cuales el profesional se coloca "en disponibilidad"; II) atención en instalaciones ajenas cuyos gastos corren a cargo de la institución; III) previsión de licencias por enfermedad y obligación de dar aviso; IV) el uso de planillas, recetarios y uniformes de la organización en la cual se desempeña; V) imposición de la nómina de pacientes por parte de la institución; VI) el carácter personal de la prestación por parte del médico (no la puede delegar en otro por decisión propia); VII) control y fiscalización con facultades sancionatorias como anotaciones en legajo, sumarios administrativos, cambio de tareas; VIII) contribución a los fines de la empresa según su actividad "normal y específica".

Estos criterios no son compartidos por todos los jueces. Algunos rechazan el vínculo laboral basados en que la sujeción a horarios y el uso de 
documentos institucionales son "mínimas exigencias organizativas". También se argumenta la admisión de reemplazantes ante ausencias prolongadas, por lo que no existiría un "carácter personal" en el trabajo, o bien que las guardias que se realizan son "disponibles". Pese al principio de la dependencia jurídica como frontera última del vínculo laboral, las prácticas judiciales no siempre consideran esa doctrina al tratar la relación de los médicos con la organización del trabajo.

I) En los casos que ponen en juego la dependencia económica o contractual, se atiende a las remuneraciones. En un caso se establece que una remuneración fija y regular bajo la forma del pago de honorarios contra facturas presentadas por los médicos, involucra un elemento de manipulación y fraude. En otro caso se atiende al hecho que la remuneración constituye un monto global, independiente de la cantidad de consultas efectuadas, lo cual traslada los riesgos de la actividad al empleador.

Asimismo, la autonomía organizativa y la asunción de costos evidencian vínculos no laborales. En un caso se afirma que la labor del médico, en tanto profesional liberal, supone un desempeño "autónomo" per se. En otro caso se considera que la posesión medios de trabajo y equipamiento propios permite al médico disponer de diferentes medios de vida, y que aún cuando los aporte a la red donde se inserta, también puede utilizarlos para atender pacientes fuera de la red.

Otros casos son próximos a los de los médicos. Uno de ellos se refiere al vínculo laboral de un contador con una empresa de transporte, donde el juez dictaminó que los profesionales pueden pactar contratos de trabajo "como una realidad cada vez más frecuente", criterio opuesto al carácter de profesional liberal aducido en relación con los médicos. En otro caso se discute sobre la locación de servicios por parte de un consultor, considerado por el Tribunal como un contrato de trabajo que debe regularse como tal, y no basta para ello que la contratación haya sido part-time, ya que ni la exclusividad ni un tipo especial de jornada laboral son condición necesaria para su existencia. También se alude aquí a la solidaridad, que 
responsabiliza por el vínculo laboral a la empresa que requirió la consultoría. En este caso, la agencia consultora fue calificada judicialmente como suministradora de mano de obra, lo cual encuadró al consultor en relación directa con la empresa usuaria de su trabajo. Esto no hubiera ocurrido si se calificaba a la agencia consultora como proveedora de servicios y no de mano de obra, lo que plantearía una relación contractual directa entre agencia y consultor.

En síntesis, sobre las fronteras del trabajo asalariado con la prestación de servicios operan representaciones sociales acerca del significado del trabajo "profesional"; en la medida que la práctica profesional puede ser organizada de diversas maneras, la inserción en instituciones plantea verdaderos dilemas simbólicos.

b) El trabajo de los transportistas

Los fleteros y camioneros con vehículo propio desarrollan sus tareas, por definición, en condiciones "físicamente" externas a las organizaciones que los contratan. Que su labor sea "externa" no significa que no esté organizada según criterios de distribución o logísticos. Por otro lado, la posesión de vehículo no siempre basta para fundar su independencia financiera.

I) Los jueces fundan el vínculo laboral de fleteros y camioneros, desde el punto de vista de la organización del trabajo, en las normas que aplican las empresas para el ordenamiento -"logística"- de la distribución: asignación de zonas, imposición de horarios, supervisión e instrucciones, carácter personal de la prestación, habitualidad en la concurrencia, actividad normal y específica de la empresa, logotipo y chaqueta, exclusividad.

Sin embargo, algunos jueces consideran que esto no es suficiente para fundar un vínculo laboral, y sostienen por ejemplo que las hojas de ruta, la coordinación horaria, el control empresario y la asignación de clientes no bastarían para configurar un contrato de trabajo. 
II) En las decisiones que apelan a la dependencia económica o contractual, se consideran la carencia de independencia financiera de los fleteros o camioneros, el carácter fijo y periódico de la remuneración, la ajenidad del riesgo empresario (por ejemplo en el caso de devolución de productos). Los criterios para rechazar el vínculo laboral se refieren a la asunción de gastos de mantenimiento del vehículo y a la responsabilidad asumida para el transporte de mercancías, la posesión de más de un vehículo en propiedad, y la posibilidad de facturar aparte la publicidad de la empresa para la que se realiza el transporte.

Tampoco aquí existen consensos que permitan asimilar unívocamente a fleteros y camioneros en la figura del trabajo asalariado. La posesión de vehículos y la "externalidad" a las organizaciones, funda para algunos jueces la autonomía organizativa y la independencia económica propias de la figura de "prestación de servicios". Sin embargo, como existe una subordinación a esquemas logísticos (y simbólicos) del contratante, y el grado de independencia económica del propietario del vehículo es siempre relativa (a sus ingresos), algunos jueces encuentran razones suficientes para fundar el vínculo dentro de la modalidad del contrato de trabajo.

En el transporte de personas, los taxistas y remiseros constituyen situaciones ocupacionales limítrofes con el sector informal de la economía. En un caso se buscó determinar la existencia de un contrato de trabajo mediado por un contrato de alquiler de un taxí. El criterio del juez se basó en aspectos contractuales, aduciendo que aún cuando se demuestre la existencia de un contrato de alquiler del automóvil, la relación que vinculó a las partes es de carácter laboral I) si no se puso límite temporal al negocio, II) si el propietario del vehículo no sólo paga el seguro del automotor sino también el seguro de vida del chofer y III) si no se cobra el alquiler por lo trabajado en día domingo. En otro caso se denegó el carácter laboral al vínculo de un remisero con una agencia, por la posibilidad de sustituir a quien ejecutaba el servicio, y porque la fijación de horarios en una organización no basta para configurar la dependencia laboral. 
Las posibilidades de control del propietario del taxi o de la agencia de remises sobre los conductores es mínima desde el punto de vista de la organización del trabajo (aunque los nuevos métodos de control electrónico y satelital permitan eventualmente ejercerlo). En cambio, los lazos contractuales pueden asemejarse al trabajo asalariado: en los contratos de alquiler de taxis los precios pactados son similares o inferiores a un salario promedio.

c) Los trabajadores a domicilio

El trabajo a domicilio en la industria de confecciones combina la autonomía organizativa con un contrato salarial. Sin embargo, en el caso analizado el carácter periódico de la remuneración no bastó para calificar el vínculo como laboral. Según el juez, el trabajador a domicilio remunerado quincenalmente no acreditó la existencia de un contrato de trabajo porque no especificó: a) qué prendas y cuántas confeccionaba, b) cómo se instrumentaban los pagos y c) qué base se adoptaba para fijar su remuneración. Asimismo, durante el juicio se constató que el trabajador retiraba mercaderías de una empresa distinta a la demandada, que entregaba mercaderías de varios clientes a un taller de planchado y confección, y que contaba en su casa con 4 ó 5 máquinas con las cuales trabajaban sus hijas. Por la descripción, la labor del tallerista se inscribe típicamente en la economía informal, en la que existe una escasa diferenciación entre esfera productiva y esfera doméstica. La posesión de herramientas, la utilización de trabajo familiar, la producción para varios clientes, son indicadores de autonomía organizativa y ello fundaría su carácter contractual independiente.

d) El pequeño comercio y los servicios independiente

En estas actividades, las relaciones de trabajo están "atravesadas" por vínculos personales. Aquí los jueces buscan deslindar esos vínculos de 
la materia del contrato, a fin de aceptar o rechazar la laboralidad en las demandas. En uno de los casos los jueces confirmaron el vínculo laboral, mediante indicios que permitían delinear la figura de un empleador. En otro caso se tuvo en cuenta explícitamente la noción de dependencia jurídica para establecer el rol del demandante en la organización del trabajo en una farmacia.

En el caso de un instructor deportivo se dió por acreditado el vínculo laboral con una organización que explota comercialmente canchas de squash, con el argumento que el instructor contribuye a la realización de la actividad y a que se obtengan los beneficios consiguientes, por lo que los honorarios abonados podía considerarse como salarios.

En dos casos relacionados con el carácter independiente de la prestación de servicios, los jueces fallaron de modo diferente según la índole de las actividades y el tipo de organización para la cual se realiza el trabajo. En el caso de un banco, se comprobó una relación laboral subordinada y permanente a través de indicios tales como la realización de tareas en forma ininterrumpida durante varios años y que se abonaran aguinaldos y vacaciones. En cambio en un caso que comprometía a un productor de seguros, se rechazó el vínculo laboral porque es una actividad que puede desempeñarse tanto en relación de dependencia como en forma independiente. Es decir que si la actividad de los productores es libre, no exclusiva y no se acredita el sometimiento a órdenes o instrucciones, configura una actividad autónoma.

e) Las fronteras sociales del trabajo asalariado

Hasta aquí se consideraron básicamente las fronteras del trabajo asalariado con el capital, donde la noción de "empleador" adquiere un sentido pleno. Sin embargo, existen actividades donde las relaciones de trabajo no pueden escindirse de los vínculos sociales; en este campo predomina el empleo informal y es difícil establecer la figura del "empleador", 
de la contraparte del contrato de trabajo.

Las fronteras del trabajo asalariado con la prestación de servicios adquieren relevancia en los trabajos que involucran la esfera doméstica, donde el deslinde de los jueces opera sobre los aspectos contractuales y, más específicamente, sobre el tipo de contrato comprometido en la relación. En el servicio doméstico y actividades afines como el cuidado de personas realizado en sus propios hogares, los jueces enfatizan la posibilidad de encuadrarlas en algún régimen diferente al laboral. En un caso se estimó la cantidad de horas trabajadas como criterio de encuadramiento dentro del régimen particular del servicio doméstico. En otro caso, el cuidado de ancianos en el hogar familiar no fue encuadrado por los jueces en la esfera laboral, ya que el hogar no puede considerarse como una organización de medios instrumentales destinados a la producción de bienes ni a la prestación de servicios, en la que pudiera subsumirse el aporte de trabajo personal (aunque como se trata de una relación contractual, puede ser regida por la Ley Civil). En otro caso se desestimó el carácter efectivamente "doméstico" del trabajo realizado, con el argumento que éste deja de ser tal cuando las tareas desempeñadas son inherentes a la profesión o industria del empleador.

En un caso referido a las tareas de enfermero profesional en el domicilio de los pacientes, los jueces mantuvieron posiciones opuestas sobre la existencia del vínculo laboral. El juez que lo rechazó tuvo en cuenta aspectos centrados en el carácter del empleador, tal como los descriptos en el párrafo anterior. El juez que aceptó el vínculo como laboral consideró en cambio aspectos de las tareas efectivamente realizadas, ya que la visión de la enfermera como profesional liberal sólo valdría para aquellos casos en que su tarea encaja dentro de la locación de obra, como cuando se la contrata para aplicar una serie de inyecciones, según una tarifa, pero cuando la enfermera cumple un horario junto al enfermo y se coloca a las órdenes de éste y de los familiares (así como del médico tratante en el aspecto técnico), el vínculo dependiente aparece mejor perfilado.

Las cooperativas de trabajo constituyen una forma societal singular 
asociada habitualmente con formas de fraude laboral: en la medida que los socios de una cooperativa lo son voluntariamente, el aporte de trabajo que realizan para la sociedad o para terceros origina conflictos en la frontera del trabajo asalariado con la prestación de servicios. Al mismo tiempo plantean también cuestiones vinculadas con la subcontratación; en dos casos se estableció que las cooperativas de trabajo no pueden actuar como colocadoras de personal en terceros establecimientos, función asignada las agencias de servicios eventuales.

Algunos vínculos laborales establecen intercambios que no suponen la prestación de trabajo remunerado. En un caso se rechazó el encuadre de un curso de capacitación laboral como contrato de trabajo, por su carácter previo a la relación de empleo, que impide identificarlo con un contrato de aprendizaje (que es de estructura laboral). Más allá de la decisión judicial, existe tensión entre trabajadores de determinadas categorías y los "pasantes" que, en el contexto actual de desempleo, son percibidos por los primeros como posibles sustitutos en el puesto de trabajo.

En los casos que involucran organizaciones del denominado "tercer sector", por lo general se rechaza el carácter laboral del vínculo establecido con organizaciones no lucrativas, dado que los servicios benévolos, amistosos y de vecindad constituyen casos de excepción de la relación individual de trabajo. En un caso se rechazó el vínculo laboral con una asociación religiosa, en base a las características contractuales no salariales de la labor realizada en ella. En otro caso que consideró el vínculo entre un jugador amateur y un club de fútbol, se rechazó su carácter laboral por circunstancias concretas propias de la dependencia jurídica: no se acreditaron condiciones de la contratación, días de trabajo, obligatoriedad de prácticas, sanciones y demás circunstancias que revelen la existencia de subordinación, ni se pactó ningún tipo de remuneración sino que sólo se abonaban viáticos. Además, las normas que regulan la actividad amateur no admiten la profesionalidad. 
Sociologias, Porto Alegre, ano 2, no 4, jul/dez 2000, p.108-143

\section{Conclusiones}

El recorrido sobre la jurisprudencia suscita inquietudes de diversa índole. La más evidente es que si se acude a los jueces para determinar la existencia de vínculos laborales, es probable que los resultados difieran considerablemente, dada la variedad de los argumentos puestos en juego para calificar esos vínculos. La evidencia obtenida a través de este material sintético permite presumir concepciones diferentes sobre el trabajo asalariado entre los jueces, que se relacionan con las fronteras analizadas: la que delimita el ámbito de la subcontratación y la que determina el ámbito de la prestación de servicios. Es que las posibilidades alternativas de realizar por sí o por terceros determinada actividad, la de contratar laboralmente o por vía civil o mercantil la realización del trabajo, funda la ambigüedad de las relaciones en este campo.

Cuando el trabajo asalariado constituía el vínculo predominante, bajo la forma prácticamente uniforme de contrato por tiempo indeterminado, sus fronteras se establecían básicamente en relación con la posibilidad de fraude laboral. Esas fronteras han perdido nitidez dado que la diversificación de tratamientos jurídicos complicó las ya fluctuantes interpretaciones judiciales sobre nociones abiertas como "actividades normales y específicas" o "...bajo la dependencia de..". La jurisprudencia parece seguir un esquema de inserción del caso concreto en un contexto de actividad determinada por ciertos "usos y costumbres", lo que habilita a los jueces a concebir con criterios diferentes actividades cuya naturaleza, en términos de los contenidos y tareas que involucran, pueden ser sustancialmente idénticas.

El discurso empresario que procura la máxima flexibilidad laboral en el sentido de reducción de costos laborales es afín con la conclusión esbozada: la ambigüedad normativa de las relaciones de trabajo es funcional a una interpretación judicial adaptativa al nuevo orden "natural" de las cosas y constituye en tal sentido una de las vías de la "flexibilidad de hecho". Sin embargo, no resulta evidente que esa flexibilidad resulte apta para fundar 
un nuevo orden laboral, por más que se revele sumamente eficaz para disolver el existente. El viejo ordenamiento aún persiste.

Pero si no se trata de la constitución de un nuevo orden laboral, ¿de qué se trata entonces?. En el terreno jurídico estaríamos en presencia, siguiendo a Alain Supiot ${ }^{15}$, de un proceso de "dualización" que alude a "los fragmentos de un derecho del trabajo del 'segundo tipo'que prospera a la sombra del antiguo. Del segundo tipo porque la mayor parte de las nociones fundamentales del derecho del trabajo (empresario, empresa, representación, huelga, incluso la noción misma del trabajador) quiebran en él" (op.cit., pág. 24). El dualismo involucra el doble standard que resulta tanto de la escisión generada en la frontera interna del trabajo asalariado por la precarización, como de la que se establece por la vía de la subcontratación.

Luego se trata de la sustitución del contrato de trabajo, sobre sus fronteras externas, por figuras que hemos definido genéricamente como contratos de prestación de servicios, que implican una derivación hacia ámbitos jurídicos diferentes, como el derecho mercantil o civil. En esta derivación se abandona la dimensión colectiva del derecho del trabajo y su carácter tutelar del trabajador individual, ya que en esos ámbitos será concebido en un status de igualdad con el que recibe el trabajo. Aquí ya no se trata de cuestiones de derecho del trabajo, sino de constelaciones jurídicas en las que la figura del trabajador desaparece.

Si la dualización involucra un doble standard, la sustitución involucra el desplazamiento del derecho del trabajo hacia contratos de índole civil o mercantil. Pero por ambas vías el trabajo pierde la articulación económica y social que le proveía anteriormente el status de asalariado. En esta encrucijada se observa el surgimiento de dos concepciones que, más allá del campo del derecho laboral, buscan conectarlo con el contexto social y económico contemporáneo. Por un lado, algunos sostienen que la evolución descripta es congruente con un proceso de modernización económica y social, al 
cual las normas jurídicas se limitarían a ofrecer "adaptabilidad" e incluso, eventualmente, la restitución parcial de algunas pérdidas a través de "reformas laborales" (como la aprobada en septiembre de 1998). Otros, por el contrario, a la luz de la multiplicación de desocupados, pobres y excluidos en años recientes, conciben el mantenimiento del derecho del trabajo en sentido clásico como una barrera que frenaría la disolución de la figura del trabajo asalariado.

Lo que importa destacar es que estas concepciones emergen en un contexto como el argentino, radicalmente diferente a los europeos, donde los argumentos del debate jurídico y social son afines a los expuestos. La diferencia central del contexto se sitúa en las instituciones del llamado Estado de Bienestar, que enmarcan el debate laboral europeo. En Argentina en cambio, esas instituciones o bien no existen plenamente, o bien las que existían estaban articuladas con el trabajo asalariado. Dicho más directamente, no es lo mismo centrar el debate en el derecho laboral cuando existe una contención social vía instituciones de otro orden, que en Argentina, donde el trabajo constituye la clave de la inserción social, la posibilidad de un servicio médico o el acceso a la seguridad previsional. Es decir, en el debate laboral en Argentina se discute siempre sobre otra cosa, en la medida que lo que se pone en juego es todo un ordenamiento económico y social. De allí también que, en el fondo, el debate laboral no puede resolverse más que parcialmente en el campo de las normas del derecho del trabajo stricto senso.

\section{Referências bibliográficas}

ABREU DE PAIVA, A.; SORJ, Bila; RAMALHO, J. R. Tercerizacao y precarizacao. Os impactos sociais da reestructuracao industrial no Rio de Janeiro. Washington, Paper presentado al XIX International Congress of LASA, September 1995.

BRYN, Jones. The Social Constitution of Labour Market. In: CROMPTON, Rosemary; DUNCAN, Gallie; PURCELL, Kate (Ed.). Changing forms of 
employement. Londres, Ed. Routledge, 1996.

GODIO, Julio (Coord.); CORTINA, R.; RIZZI, S.; ROBLES, A. J. La incertidumbre del trabajo. Buenos Aires, Ed. Corregidor, 1998.

GOLDíN, Adrián. El concepto de dependencia laboral y las transformaciones productivas. Ponencia presentada en Actualidad y contenido del concepto de dependencia laboral, XII Jornadas Nacionales de Derecho del Trabajo y de la Seguridad Social, realizadas por la Asociación Argentina de Derecho del Trabajo y de la Seguridad Social. Buenos Aires, septiembre de 1995.

NOVICK, M.; GALLART, M. A. (Coord.). Competitividad, redes productivas y competencias laborales. Buenos Aires, Ed. CINTERFOR-OIT y Red de Educación y Trabajo, 1998.

OIT. Informe V (2B) Addendum. Comisión del Trabajo en Subcontratación. 86 reunión. Ginebra, junio de 1998.

PALOMINO, Héctor. Articulaciones entre formalidad e informalidad en la Industria de la Construcción. Foro de Informalidad y exclusión social, organizado por OIT/ SIEMPRO en Buenos Aires, agosto de 1998. Buenos Aires, Edit. FCE. febrero de 2000.

PAWLOWSKI DE POSE, A..L. La ajenidad del riesgo como factor tipificante. Derecho del Trabajo, Buenos Aires, n.5, p.1000-1001, mayo 1998.

SUPIOT, Alain. ¿Por qué un derecho del trabajo?. Documentación Laboral, España, n.39, 1993.

VAZQUEZ, Vialard, A. El concepto de dependencia laboral frente a nuevas prácticas contractuales. ¿Debe desaparecer o transformarse? Ponencia presentada en Actualidad y contenido del concepto de dependencia laboral, XII Jornadas Nacionales de Derecho del Trabajo y de la Seguridad Social, realizadas por la Asociación Argentina de Derecho del Trabajo y de la Seguridad Social. Buenos Aires, septiembre de 1995.

WALTER, J.; SENÉN, González, C. Modernización tecnológica sistémica, políticas de recursos humanos y relaciones laborales en la telefonía argentina tras la privatización. Documento presentado en el II Congreso Latinoamericano de Sociología do Trabalho. Sao Paulo,1 al 5 de diciembre de 1996. 


\section{Síntesis}

El estudio de las formas contractuales y la organización del trabajo, revela una convergencia de procesos registrados en los países centrales con los que vienen siendo tratados desde hace varias décadas por la sociología latinoamericana. La situación argentina constituye, al respecto, un foco de interés para el análisis, ya que la expansión de la precariedad y de la desocupación en los '90 tendieron a desestructurar un mercado de trabajo en el que la modalidad asalariada, estable y protegida, se había consolidado desde mediados de siglo.

La jurisprudencia reciente muestra el impacto de aquellas tendencias sobre las formas de representación simbólicas del trabajo en el campo jurídico, donde las decisiones de los jueces intervienen sobre las fronteras contractuales y organizativas del trabajo asalariado. Esta reflexión sobre diversas modalidades de inserción laboral, conecta temas instalados en un campo común a la sociología, el derecho y la economía, por lo que puede contribuir a afianzar la colaboración interdisciplinaria en ciencias sociales. Al mismo tiempo, el enfoque adoptado permite indagar las posibilidades de fertilización conceptual entre diversas tradiciones clásicas en sociología, y de su aporte potencial para la comprensión de la articulación del trabajo en las sociedades contemporáneas. 